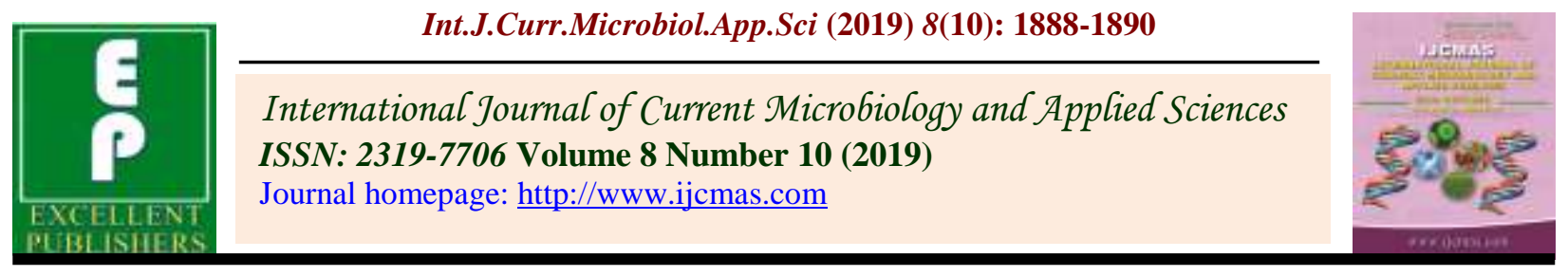

Case Study

https://doi.org/10.20546/ijcmas.2019.810.218

\title{
A Rare Case of Urinary Myiasis in an Immunocompetent Female
}

\author{
Yasmeen Fatima*, Ameena Afreen, Mohammed Nasar and K. Nagamani \\ Gandhi Medical College, Nimboliadda, Kachiguda, Hyderabad-500027, India \\ *Corresponding author
}

\section{A B S T R A C T}

\section{Keywords}

Immunocompetent,

Fannia, Musca,

Clogmia,

Sarcophaga,

Lucilia, Eristalis,

Calliphora,

Psychoda

\section{Article Info}

Accepted:

15 September 2019

Available Online:

10 October 2019
Myiasis is a term used to describe the invasion of tissues or organs of vertebrates with the larvae of dipterous flies. It is largely a problem in livestock, human infestations in rural tropical areas of the globe is uncommon. Myiasis may involve the skin, eyes, nasal passages, gastrointestinal and genitourinary tracts. Urinary myiasis is caused mainly by larvae of Fannia scalaris, Musca, Sarcophaga, Lucilia, Wohlfahrtia, Calliphora. Cases of urinary myiasis are rare; however, it may occur in immunocompromised hosts, with previous urologic instrumentation or those with poor hygiene. This report presents a case of female patient complaining of intermittent passage of 3-5 small, motile, dark-colored worm-like organisms in urine since last 3 months. She was unmarried aged 24 years old, immunocompetent $\&$ healthy. She was subjected to a full questionnaire sheet and investigations such as $\mathrm{CBC}$, urine analysis. Collected larva from urine samples were examined macroscopically and microscopically. The examined larva belonged to $C$. albipunctata. Ivermectin was prescribed to the patient with complete disappearance of larva from urine. The study throws some light on the medical importance and management of urinary myiasis. Observance of personal hygiene during defecation and urination is essential to prevent contamination of this type of myiasis.

\section{Introduction}

Urinary myiasis is defined as the invasion of urinary tract of vertebrates by larvae of Diptera order of flies. It is largely a problem in livestock, human infestations in rural tropical areas of the globe is uncommon ${ }^{1}$. Myiasis may involve the skin, eyes, nasal passages, gastrointestinal and genitourinary tracts. Urinary myiasis is caused mainly by larvae of Fannia,Musca,Clogmia,Sarcophaga,Lucilia, Eristalis,Calliphora,Psychoda ${ }^{1}$. Cases of urinary myiasis are rare and tends to affect the severely immunocompromised, those with poor personal hygiene, and those living in or visiting environments with poorly sanitized water sources. Myiasis is commonly seen in developing countries with increased prevalence in open wounds (cutaneous myiasis) ${ }^{1}$. Invasion of the urinary tract tends to 
occur primarily through inoculation with contaminated water sources and affects females more commonly than males ${ }^{1,2}$. Urinary myiasis in a healthy, immunocompetent, non-instrumented female has not been previously reported.

\section{Case presentation}

This poster presents a case of female patient attending our hospital, complaining of intermittent passage of 3-5 small, motile, darkcolored worms in urine since last 3 months. She was unmarried aged 24 years old, immunocompetent \& healthy. She denied any knowledge of a source of infection, denied recent urethral catheter placement, genitourinary or pelvic procedures, or prior genitourinary pathology. On physical examination, the patient was noted to be wellappearing, well-groomed, appearing her stated age. There was minimal suprapubic tenderness on palpation.

\section{Investigations}

The urine sample provided by the patient at the initial visit revealed small, roughly $0.5 \mathrm{~cm}$ dark, motile larvae on visual inspection. Urinalysis was normal and urine culture was negative.

\section{Results and Discussion}

Microbiological analysis identified the larvae as belonging to the Diptera order of flies.

The examined larva belonged to Clogmia albipunctata.

\section{Treatment and follow up}

Ivermectin was prescribed to the patient with complete disappearance of larva from urine. Treatment was initiated with a single dose of ivermectin (3 $\mathrm{mg}$ oral tablet). The patient denied passage of larvae 1 week after completing ivermectin. Cystoscopy was performed a few weeks later, and demonstrated normal bladder mucosa and orthotopic ureteral orifices without any evidence of larvae or other lesions suggestive of an acute or prior infection. The patient has since remained clear. She will follow-up in 1 year with a urine culture and urinalysis.

This study throws some light on the medical importance and management of urinary myiasis. Improving personal hygiene \& living in well sanitized environments is essential to prevent contamination of this type of myiasis (Fig. 1 and 2).

Fig.1

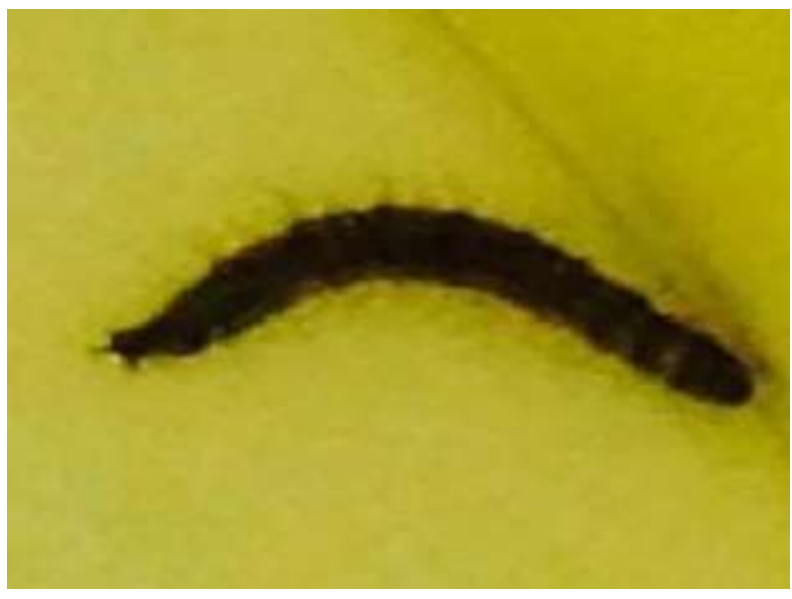


Fig.2

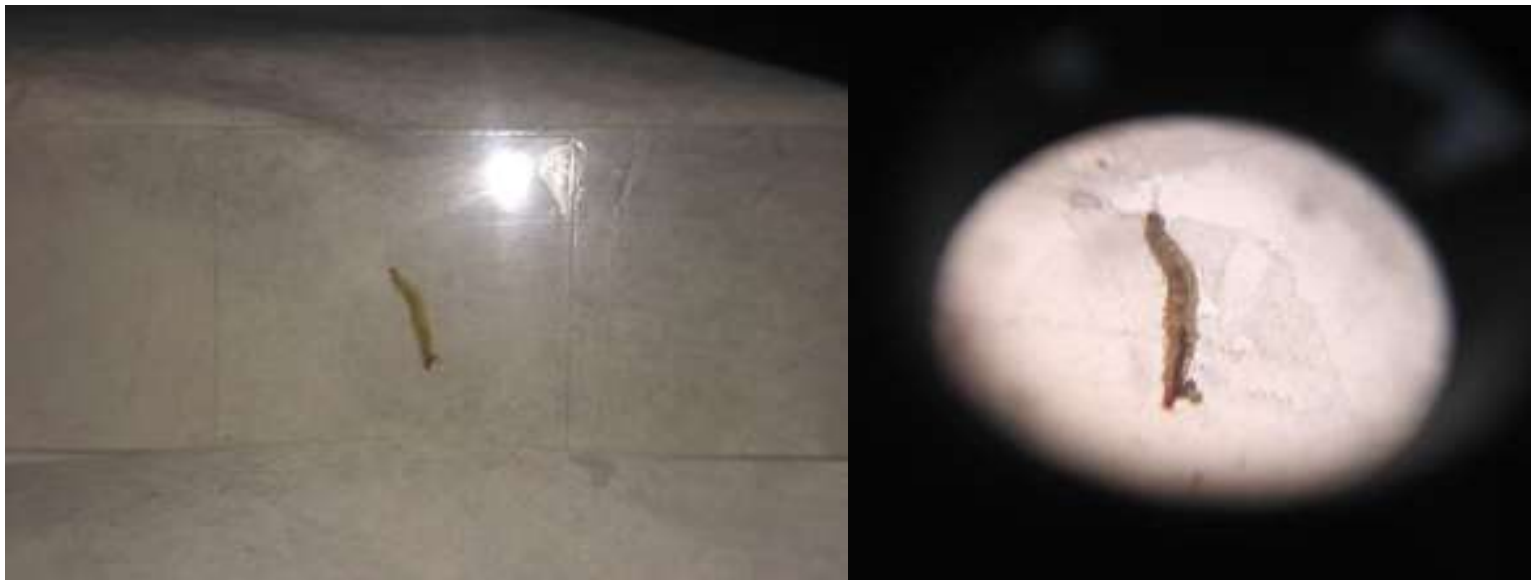

In addition to $C$. albipunctatus, several urogenital myiasis cases caused by other species were reported in the past. For example, urogenital myiasis caused by Psychoda albipennis was reported in a 10year-old girl, and Eristalis tenax was reported in a 58-year-old woman ${ }^{4,5,6,7}$.

\section{References}

Day JF, Edman JD, Kunz SE, et al., Chapter 4 Direct injury: phobias, phychoses, annoyance, allergies, toxins, venoms, and myiasis. In: Eldridge BF, Edman JD, eds. Johns Edition Medical entomology: a textbook on public health and veterinary problems caused by arthropods. Davis, CA: Springer Science \& Business Media, 2003: 134.

Hyun DY, Cain MP, Blue-Hnidy DE, et al., Urinary myiasis associated with ureteral stent placements. Pediatr Infect Dis J. 2004; 23: 179-81.

Samuel MI, Taylor C. An unusual and unsettling place for a worm. Int J STD AIDS, 2010; 21: 524-5.

Güven E, Kar S, Doğan N, et al., [Urogenital myiasis caused by Psychoda albipennis in a woman]. Turkiye Parazitol Derg., 2008; 32:174-6.

Wakid MH. A laboratory-based study for first documented case of urinary myaisis caused by larvae of Megaselia scalaris (Diptera: Phoridae) in Saudi Arabia. Korean J Parasitol., 2008; 46: 33-6.

El-Badry AA, Salem HK, El-Aziz Edmardash YA. Human urinary myiasis due to larvae of Clogmia (Telmatoscopus) albipunctata Williston (Diptera: Psychodidae) first report in Egypt. Journal of vector borne diseases. Sept 2014.

Demir AD, Iraz M, İpek DN. Urogenital myiasis caused by Psychoda albipennis in a child. Turk Pediatri Arsivi. 2015 Mar; 50(1):65 \pm 8 . PMID: 26078699.

\section{How to cite this article:}

Yasmeen Fatima, Ameena Afreen, Mohammed Nasar and Nagamani, K. 2019. A Rare Case of Urinary Myiasis in an Immunocompetent Female. Int.J.Curr.Microbiol.App.Sci. 8(10): 18881890. doi: https://doi.org/10.20546/ijcmas.2019.810.218 